\title{
Extending belief research to adult basic education: an exploration of some adult educators' beliefs about numeracy and its teaching
}

\author{
Sonja Beeli-Zimmermann
}

Received: 18 July 2019 / Accepted: 4 October 2019 / Published online: 31 October 2019

(C) The Author(s) 2019

\begin{abstract}
While belief research has become an integral part of the educational research agenda, it has been uneven. One neglected area is the beliefs of adult education teachers. Focusing on five such teachers working in adult basic education and teaching numeracy in Switzerland, this exploratory study uses different data to describe their beliefs about numeracy and its teaching. It is shown that this group holds clearly different views from other groups of adult teachers and it is argued that extending belief research to this target group using different approaches could contribute to a wider knowledge base on beliefs in general.
\end{abstract}

Keywords Beliefs $\cdot$ Mathematics $\cdot$ Numeracy $\cdot$ Adult basic education 


\section{Überzeugungen (beliefs) von Kursleitenden in der Erwachsenenbildung: Eine explorative Studie zu Numeralität}

Zusammenfassung Die Belief-Forschung stellt heute einen integralen Bestandteil erziehungswissenschaftlicher Forschung dar, wobei sie sich kaum der Erwachsenenbildung annimmt. In dieser explorativen Studie werden die mathematischen Vorstellungen (beliefs) von fünf Kursleitenden beschrieben, welche in der Schweiz in der Grundbildung tätig sind und Alltagsmathematik unterrichten. Dabei wird gezeigt, dass sich die Vorstellungen dieser Gruppe deutlich von den Vorstellungen anderer Lehrpersonen in der Erwachsenenbildung unterscheiden. Auf dieser Basis wird argumentiert, dass eine systematischere Ausdehnung der Belief-Forschung auf die Erwachsenenbildung, insbesondere im Bereich Grundbildung, mit dem Einsatz von unterschiedlichen Instrumenten einen wichtigen Beitrag zu deren Weiterentwicklung beitragen könnte.

Schlüsselwörter Überzeugungen (beliefs) · Mathematik · Numeralität · Erwachsenenbildung

\section{Introduction}

Teachers' beliefs have become an integral part of the educational research agenda. Both students' as well as teachers' beliefs have been studied with various methods and perspectives (Fives and Gill 2014). While mathematical belief research enjoys a high level of interest in the context of school education, the subject has received less attention in the adult education sector. Given the growing importance of lifelong learning and the fact that teachers' beliefs relate to the quality of their classes, there is a need to know more about the beliefs held by this specific group of teachers (Schlöglmann 2007). This article aims to contribute to building this knowledge. It provides results from an exploratory study with some Swiss adult education teachers and aims at providing initial insights to the following guiding question: What are key characteristics of beliefs about numeracy and its teaching held by Swiss adult basic education teachers?

\section{Background}

\subsection{Belief research}

Beliefs are often described as "filters" (Pajares 1992) through which teachers see the world and according to which they act. And even though belief research has gained in importance, there does not exist a generally accepted definition yet (Goldin et al. 2009). Pajares' description of beliefs as a "messy construct" still applies and a key question is how the term differs from others such as values, attitudes, conceptions or implicit theories. While beliefs contain both cognitive and affective elements, they 
are not identical with either. Reusser et al. (2011) characterize beliefs as follows: (i) they are intentional and organized in the form of clusters; (ii) they have an affective component; (iii) they are some form of individually internalized habitus; (iv) they are relatively stable and resistant towards change; (v) they are implicit and difficult to access.

Particularly the last aspect is challenging for empirical work, as it has to find answers to the question of how subconsciously held beliefs can be identified (Pehkonen and Törner 2004). While the entire spectrum of qualitative and quantitative methods is used in belief research, large quantitative surveys and small qualitative studies dominate. Generally, the quantitative approach relies on questionnaires and factor analysis aiming to identify dimensions of beliefs. Qualitative studies try to examine beliefs in a broader context and describe how they interact with other factors (Goldin et al. 2009). While this study clearly fits the characteristics of the latter, it also makes use of a questionnaire (Swan 2006) in order to facilitate a systematic comparison of its participants and to explore the usefulness of a multimethod approach in this context.

\subsection{Mathematical beliefs}

Beliefs are held about a variety of issues such as learning in general, a specific subject or individual students. Reusser et al. (2011) distinguish epistemological beliefs about contents and processes of learning, personal beliefs about teachers and students and contextual beliefs about school and society. Beliefs about mathematics contain views of the nature of mathematics, such as "mathematics is precise calculation", its origin and relationship with other disciplines, and also include notions of how it is taught and learned. They can therefore be considered to be epistemological beliefs. They represent a particularly well researched area within mathematical belief research (Leder et al. 2002), not least of all because of affective issues such as mathematics anxiety. More recently, Forgasz and Leder (2008) document the increasing interest and activities in this research field and present an overview of undertaken studies. They conclude that more work has been done on primary teachers than on secondary levels and more on teachers' beliefs about learning than about content areas. They also state that views of the nature of mathematics and those of its teaching and learning are related, but that this is not a straight forward relationship, rather it is "dictated" by circumstances (Forgasz and Leder 2008, p. 187).

As the term mathematics is used to describe both, the discipline and the school subject, mathematical beliefs can relate to either or both of them. Relatively few studies addressing mathematical beliefs have broached this differentiation (Beswick 2012). However, this issue is even more complex in the field of adult basic education, as mathematics in this context is often used synonymously with terms like numeracy, quantitative literacy and basic or everyday mathematics. Without going into a detailed discussion of these terms (this is done for example by O'Donoghue 2002) they will be differentiated in this paper: The term "mathematics" is used by the author when it stands for the entire discipline and is used in this encompassing sense when reporting research results or talking about mathematics classes in gen- 
eral. The term "numeracy" is used whenever the participants stand in the foreground as it reflects the context they work in and not least of all how they see themselves. ${ }^{1}$

One key-question is the relationship between beliefs held and how they translate into teaching practices. Ernest (1989) describes three philosophies of mathematics and argues that each has practical outcomes in the classroom. He calls his first view a problem solving view where mathematics is considered to be a dynamic and continually expanding field, rather than a finished product. Its development is driven by specific problems. The second is the Platonist view where mathematics is a static, unified body of knowledge, a well-structured product that is discovered, not created. The third is the instrumentalist view in which mathematics is a useful but unrelated collection of facts, rules and skills. Many studies in mathematical belief research are based on or refer to this threefold view of mathematics, often in combination with a classification of teaching approaches (among them Liljedahl 2009; Swan 2006; Pehkonen and Törner 2004). More specifically, when trying to identify effective teachers of numeracy at the primary school level, Askew and colleagues (Askew et al. 1997) describe a connectionist, a transmission, and a discovery orientation towards the teaching of mathematics. For a teacher taking a connectionist orientation, teaching mathematics is based on a dialogue between teacher and students. In a transmission oriented approach, teaching is based on verbal explanations and the discovery perspective stresses practical activities.

One key insight from research identifying and comparing different views of mathematics and its teaching is that teachers rarely hold one pure view, but often a combination with one dominating perspective. With regard to adult education teachers, Henningsen and Wedege (2003) used a combination of different data to examine 212 Danish teachers' beliefs in relation to mathematics. The participants wrote a short essay on mathematics, completed a biographical questionnaire and spontaneously identified a listed value items they associated with mathematics. Using factor analysis on the value item data, Henningsen and Wedege (2003) identified what they called an "openness/concrete", a "mystery/puzzle" and a "control/discipline" dimension of mathematics. They found that both the type of educational institution as well as the type of mathematical training are associated with the first dimension, while neither age nor gender play a significant role. Similarly, Nisbet and Warren (2000) used factor analysis on data they collected with a Likert-scale survey and identified what they called a "static" and a "mechanistic" view of mathematics. They also identified a "traditional" and "contemporary" view of teaching mathematics and found that within their target group of grades 1-7 teachers both a static view of mathematics as well as a contemporary view of teaching increase with the grade level taught. The teachers' mathematics qualifications had no effect on their views. Similarly, Archer (2000) found that there are marked differences in the epistemological views of mathematics between primary and secondary school teachers. The former tend to see mathematics as linked to students' experiences outside the classroom and other aspects of the curriculum, whereas the latter see it more self-contained, with an orderly, logical structure.

\footnotetext{
1 Many of the participants stressed that they were not mathematicians or mathematic teachers, but that their area of expertise was numeracy.
} 


\subsection{Contextualizing the study}

The educational system in Switzerland is characterized by its high decentralization and a high status afforded to vocational education. The main responsibility for education lies with the cantons which coordinate their work at the national level (Swiss Conference of Cantonal Ministers of Education 2018). The delegation of authority to the cantons results in a "complicated situation with respect to the responsibility for the promotion of measures in the field of [adult] basic skills" (Schräder and Gräminger 2010, p. 13, translation by the author). The key-player in this field is the national umbrella organization namely the Swiss Federation for Adult Learning (SVEB). ${ }^{2}$ This organization has, among others, piloted a training course for numeracy teachers, ${ }^{3}$ contributed to the initiation of and now manages the Swiss numeracy network ${ }^{4}$ and developed a model for the promotion of basic skills at the workplace ${ }^{5}$. Still, teaching numeracy in adult basic education is not (yet) very prominent in Switzerland and only a limited number of teachers work in this field. The novelty of the subject as well as the delegation of authority means that most initiatives relating to numeracy teaching are based on the needs of specific institutions or communities: Curricula are developed within specific contexts and generally those who do teach numeracy enjoy a great deal of freedom in designing their courses as long as they meet the needs defined by those in charge. Most numeracy teaching takes place in German as a second language classes or in the context of contributing to the integration of migrants into the labor force. These classrooms are marked by the students' heterogeneity not only in terms of age and their level of education, but also with regard to their linguistic and cultural background. However, the majority of students are reportedly characterized by low levels of education and negative school experiences (oral communication by various participants). Similarly, the adult educators themselves present a very heterogeneous group: As there is no initial training to become an adult educator in Switzerland, all of them have different educational paths, many starting with an apprenticeship in a specific industry and further training in adult education. Some of them trained as German as a second language teachers for adults, others might have a degree as primary school teachers. Generally, they have neither specific training in mathematics nor in mathematics teaching-in some cases they might be forced to teach numeracy because their employer has decided

\footnotetext{
${ }^{2}$ Basic information about the organization and the field of continuing education and training in English is provided at https://alice.ch/en/continuing-education-in-switzerland/ (Access on July 12, 2019).

3 The numeracy training course aimed at adult education teachers was conducted four times between 2008 and 2014. It encompassed eight days of courses within one year, some 45 individuals attended it in total. It is currently not offered due to limited interest.

${ }^{4}$ More information about the network is available in German at: http://www.netzwerk-alltagsmathematik. $\mathrm{ch} /$ (Access on April 25, 2019). At the time of the call it contained some 100 members from various institutions. It organizes one to two events per year during which a specific issue of teaching numeracy is addressed in a three hour workshop.

${ }^{5}$ Basic information in English about this project is available at https://alice.ch/en/services/go-upskillingon-the-job/, (Access on July 12, 2019) more specific information in German is available at https://alice.ch/ de/dienstleistungen/go-upskilling-am-arbeitsplatz/go-modell/ (Access on July 12, 2019).
} 
to include numeracy in language classes (oral communication by the manager of a provider of basic skills courses).

Overall, it can be said that in Switzerland the field of numeracy in adult basic education is only emerging, with the Swiss numeracy network as a key point of reference albeit a low key one. On the one hand it is being developed in a bottom-up approach by motivated and interested individuals and institutions, on the other hand it is driven by the political will ${ }^{6}$ to integrate migrants into the work force. Given the size of the country, key individuals know each other if not personally then by name.

\section{Study design}

The overall nature of the presented study is exploratory-both with respect to the addressed content area and the instruments used. It relies on a short questionnaire as well as verbal data which were gathered together with participant drawn images the results of which are reported elsewhere (Beeli-Zimmermann 2014). Methodologically, the focus of this article is on the complementarity of the questionnaire and verbal data. This procedure has been found to be beneficial in belief research before (Pehkonen and Törner 2004), not least of all as one instrument can compensate potential weaknesses of the other(s). More specifically the results from the questionnaire will be used to identify key characteristics of the participants' beliefs, while the results from the interviews will illustrate what they mean to the participants.

\subsection{Instruments used}

Data reported in this study have been collected through semi-structured interviews and a questionnaire developed by Swan (2006) on the basis of Ernest (1989) and Askew et al. (1997). The questionnaire-one of the few focusing on adult education-contains nine statements describing different conceptions of mathematics and its teaching and learning which need to be weighed by the participants (see Table 3 in the Appendix for the complete questionnaire). The interviews addressed the participants' education as well as specific aspects of teaching numeracy to adults and included watching and commenting upon five video sequences which were presented on a portable computer. More specifically they were asked the following: What happened in the episode you've just seen? What does it remind you of? Do you have any other concluding comments to what we've just seen ${ }^{7}$ While the original videos taken from an educational database (unterrichtsvideos.ch 2008) cover

\footnotetext{
6 The integration of migrants is a task shared by the federal and cantonal governments with increasing importance being allocated to the latte. More specific information in German on the current programs is available at https://www.sem.admin.ch/sem/de/home/themen/integration/kip/2018-2021.html (Access on September 20, 2019).

7 These questions reflect the intended use of the videos, namely, to elicit the participants' memory from their time as students as these experiences are considered to be fundamental for the development of beliefs. However, since the depicted scenes differed fundamentally from what they have experienced this purpose could not be met. However, an issue that was repeatedly brought up when talking about the videos was the question of how what they had seen differed from the contexts in which they work now.
} 


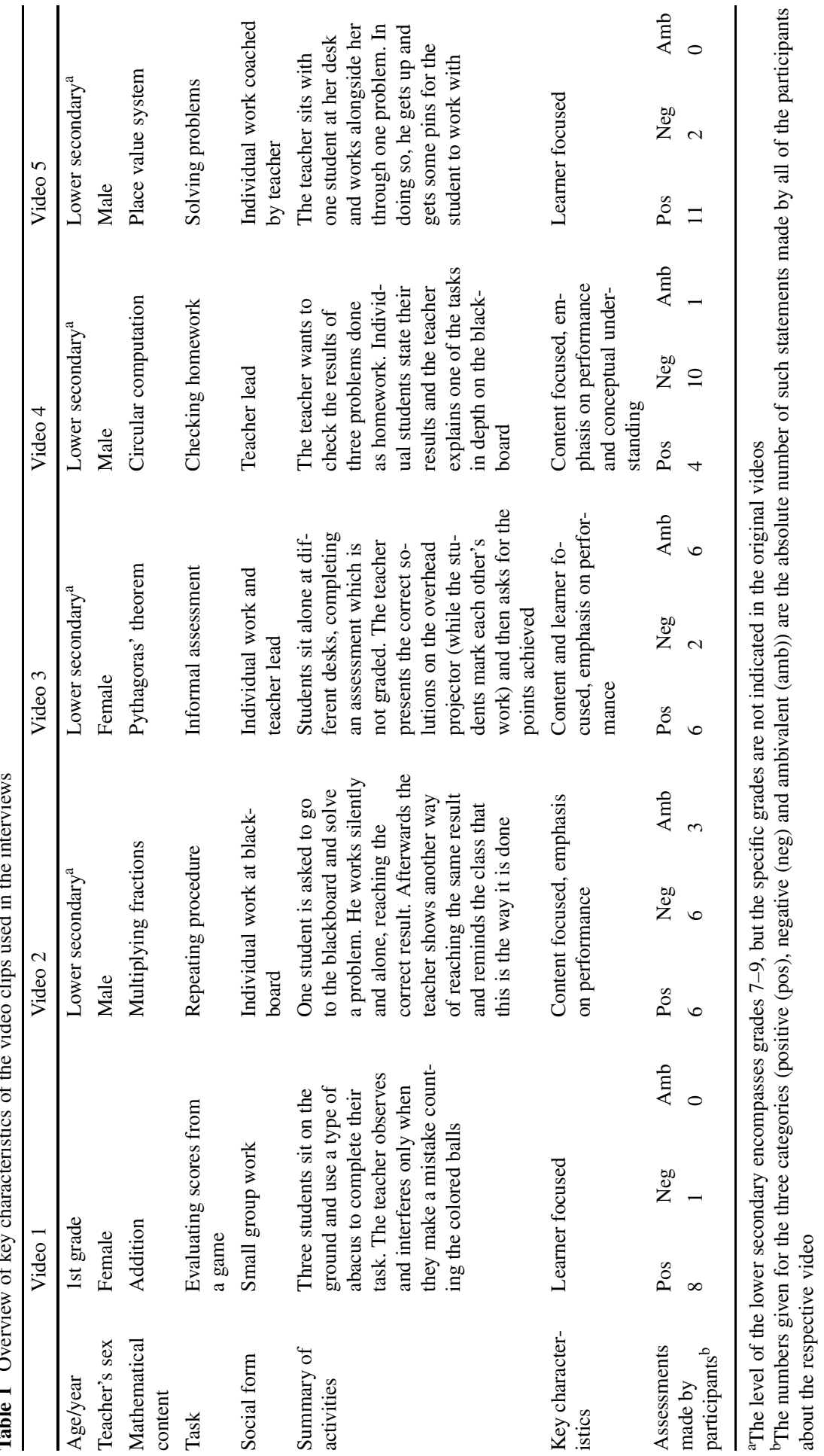


an entire mathematics lesson, specific moments were selected for the interviews. Selection criteria were the variety of situations in the classroom, the teacher's age and gender as well as the students' age (see Table 1). The questionnaire was chosen because it addresses views of mathematics as well as its teaching and learning and because it uses a weighing approach "rather than asking [the participants] to try to choose between what they perceive to be false dichotomies" (Fang 1996, cited in Swan 2006). This reflects the previously reported finding that teachers generally hold a combination of different views rather than one pure view of mathematics. However, it also entails an understanding of mathematics as a school subject, which is not completely aligned with this paper's focus on numeracy and has some limitations with regard to the available information about the participants for which its results are reported ${ }^{8}$. Yet because the threefold view of mathematics continues to be employed in belief research and because it allows for a direct comparison with the participants of this study, the somewhat dated questionnaire is still considered to be appropriate, not least of all as it allows for moving beyond individual qualitative descriptions of beliefs based on interview data. ${ }^{9}$

\subsection{Procedure and participants}

Data for this study were collected in the summer of 2012. The participants were identified after responding to a call for interested teachers distributed through the Swiss numeracy network (see footnote 4). Being the only national network in this field it brings together individuals interested or working in the field of numeracy from both public and private institutions representing practitioners as well as academics. Out of the twelve respondents eight were identified as suitable candidates ${ }^{10}$ and were contacted to agree on a date for the first interview. At the end of the first interview the date for the second interview was agreed upon. The questionnaire was completed at the end of the second interview in the presence of the interviewer. The interviews were conducted in Swiss German, recorded digitally and then transcribed into standard German. They lasted some 80 min on average (minimum $60 \mathrm{~min}$, maximum $140 \mathrm{~min}$ ).

Among the eight participants there was a subgroup of five individuals (TP1-TP5, two women, three men) who have all undergone the specific numeracy training as described in footnote 3 . Two key content elements of the training were (1) sensiti-

\footnotetext{
8 While Swan does not provide any information on his participants' age or gender, his target group of teachers at English colleges of further education shares reportedly shares many similarities with the participants of this study, particularly their own diverse educational experiences, the work context of vocational studies and teaching students older than 16 (oral communication by British colleagues).

9 Moreover, the analytical scheme used for the analysis of the participant drawn images also refers to Ernest (1989) therefore making it an appropriate reference from a methodological perspective to ensure analytical consistency among the different sets of data (Beeli-Zimmermann 2014, 2015).

10 Candidates considered "unsuitable" included people who were not directly working as numeracy teachers, but just expressed general interest in the study.
} 
zation for the specifics of numeracy, ${ }^{11}$ such as its invisibility in everyday life; and (2) contrasting the teaching and learning of numeracy with that of language in order to understand parallels and differences (Kaiser 2009). ${ }^{12}$ Didactically building on the participants' previous experiences as adult education teachers was a corner stone of the training and they were encouraged to transfer some of their key principles of teaching German as a second language to their teaching of numeracy (oral communication by the course leader). In addition to having undergone the same training, at the time of the interviews, all five participants worked as course leaders in adult basic education though to different extents, while the other three were engaged in fields such as private tutoring. More specifically, three of the participants (TP1, TP3 and TP5) were mainly working as German as a second language teachers, while TP2 was working with unemployed and TP4 as a trainer of numeracy teachers and public relations consultant. At that time they were on average 50 years old (minimum 43 , maximum 57, see Table 2). Their educational backgrounds are as follows: primary school teacher (TP1), chemical technician (TP2), communication specialist (TP3) and commercial clerk (TP4 and TP5, a more detailed description of the participants can be found in Beeli-Zimmermann 2015). So while this subgroup is homogenous in terms of their specific training in numeracy for adults and their age, they differ with regard to their teaching situation, and more widely in their educational background and previous work experiences. Having participated in and contributed to some of the network's events in the past years as well as being in contact with its key players, the author has gained an insight into the small group of Swiss numeracy teachers. She feels that, in spite of its reduced size, the selected participants constitute an appropriate sample of this specific population: They not only represent the diverse educational backgrounds and working contexts of Swiss adult education teachers in general, but also the fact that none of them have any specific training in the field of mathematics.

\subsection{Data analysis}

The interviews were analyzed with the method of qualitative content analysis (Mayring 2014). This method is based on a systematic application of an objective coding scheme. The codes used for the analysis of the interview transcripts were largely developed inductively and covered broad thematic areas such as biography, teaching mathematics or videos, which all contain numerous subcodes specifying the overarching themes. More specifically, for the discussion of the videos, the following three subcodes have been defined in alignment with the questions asked: observations, interpretations and reflective/questioning comments. The code observations include all statements related to what the interviewees saw on the

\footnotetext{
11 While the course leader/author consequently uses the German term "Alltagsmathematik" (everyday mathematics) therefore stressing contextual and personal aspects, he refers to the English term numeracy and defines it very broadly as the ability to deal with numbers, data, charts, tables or plans in everyday life-independent of specific contexts (Kaiser 2009).

12 For German speakers the more recent version of the course outline and some of the materials used might be interesting. It is available at https://alice.ch/fileadmin/Dokumente/Grundkompetenzen/Alltagsmathe_ Handbuch.pdf (Access on: July 12, 2019).
} 
videos, such as activities by the teachers or students. Interpretations comprise of those statements where general conclusions were drawn from the observations, for example: "For me this is a modern way of teaching, this one to one coaching." (TP1) And finally the reflective/questioning comments included statements that related to the participants' own experiences or critical questions, such as: "Well this competitiveness is alien for me. I don't do that in my classes. I try not to expose anyone that way" (TP5, referring to a student in the second video who had to solve a problem by himself at the blackboard).

Overall assessments for each video were derived on the basis of the participants' individual statements. If comments included unambiguous assessments meaning that they contained evaluative words such as "better", "bad" or comparative phrases like "more" or "less", they were coded as being either positive or negative. For example: "This was definitely the most pleasant of all videos." (TP5) Or: "This has left the worst impression, this situation." (TP3) If a participant said something positive about a video but modified it in the same sentence or made a mediocre assessment, this was coded as ambivalent, for example: "I'm not so convinced by this approach." (TP3). Each participant's evaluative comments were analyzed separately for each video and an overall assessment on the basis of the total of positive, negative and ambivalent statements was made. The total of these statements are included in the last line of Table 1.

\section{Findings}

First the data from the questionnaire will be analyzed, then specific issues deriving from the interviews will be presented in order to illustrate the questionnaire results.

\subsection{Questionnaire results}

Results of mathematical belief research based on the threefold characterization of mathematics are often presented in equilateral triangles. In this paper this is done with the help of Tri-plot, a Microsoft Excel spreadsheet developed by Graham and Midgley's (2000), which allows for a visual presentation of tri-variate data. ${ }^{13}$ On the basis of the participants' weighted statements, the mean weighting is calculated for each dimension, namely transmission, discovery and connectionist. Therefore each dot represents the extent to which the respective participant holds transmission, discovery or connectionist oriented views of mathematics and its teaching and learning (e.g. the position of TP5 in Fig. 1 is determined by a view that is $8 \%$ transmis-

\footnotetext{
13 The original tri-plot was developed in the context of earth sciences to create different types of triangular diagrams. Swan (2006) used the conventional diagram which allows to represent the proportion of three aspects, in his case views of mathematics. The latest version of the required excel sheet as well as the related documentation can be downloaded at https://www.lboro.ac.uk/microsites/research/phys-geog/triplot/index.html (Access on July 11, 2019).
} 


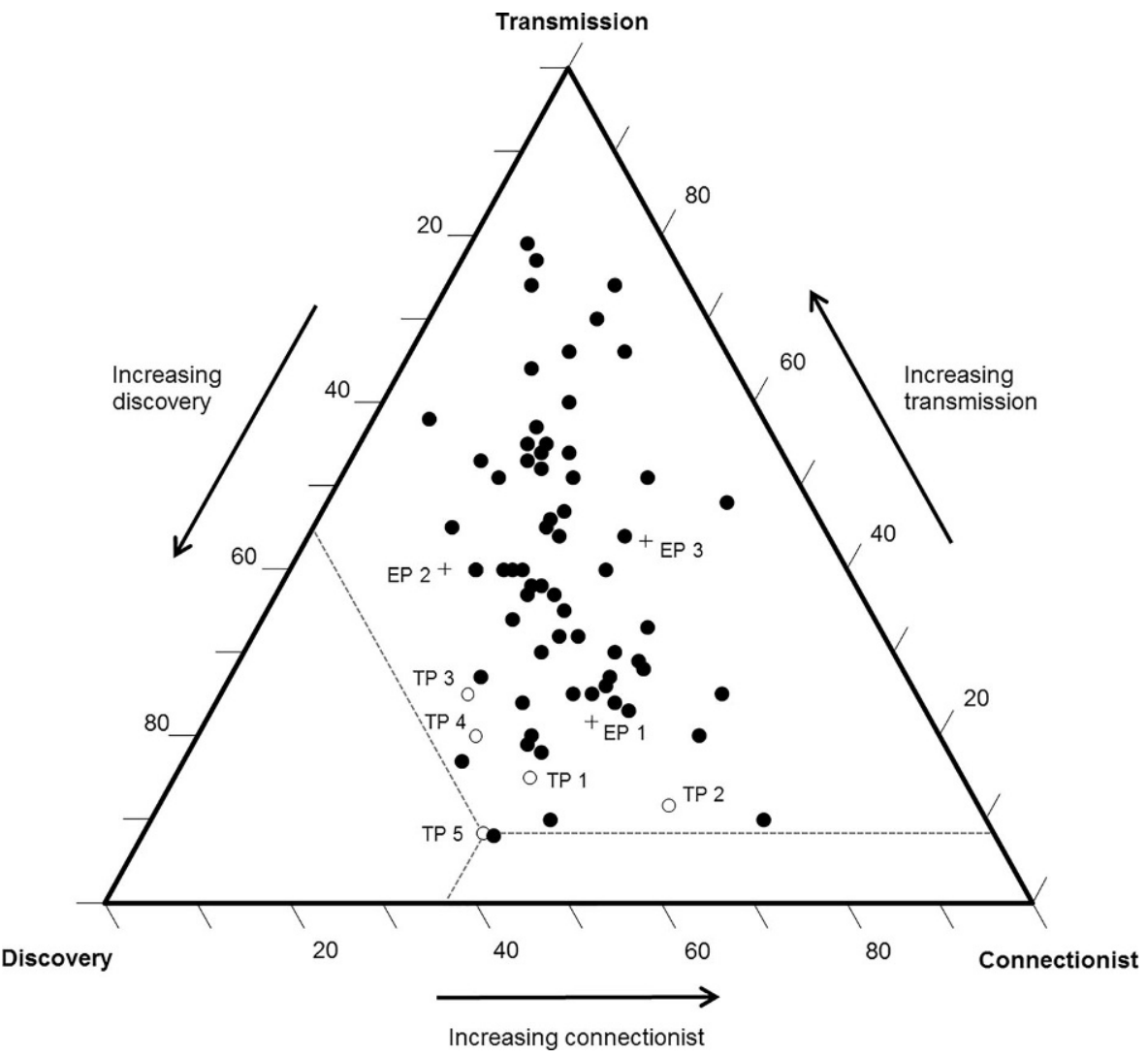

Fig. 1 Tri-plot showing the mean weightings for each participant of the different groups Swan's original group, $\bigcirc$ five participants presented in this study (test participants, TP1-TP5), + three participants omitted for the detailed analysis in this study (excluded participants, EP1-EP3))

sion, 55\% connectionist and 37\% discovery). Fig. 1 presents Swan's initial results ${ }^{14}$ complemented with the results of this study. It is noteworthy that the participants of this study are oriented towards the constructivist side of the triangle, as Swan has summarized the discovery and connectionist dimensions (an indication to Swan's understanding of the term can be gathered from the statements in his questionnaire which address these two dimensions which is provided in Table 3 in the Appendix). It is also worth noting that the three individuals originally excluded from this analysis for the variance in their background (EP1-EP3, represented as + in Fig. 1) are

\footnotetext{
${ }^{14}$ In order to be technically able to present Swan's data and the findings in one figure, the coordinates of his participants had to be derived by measuring them in Fig. 1 in the original article. Both the manual overlay of the original and the recreated plots as well as the mathematical comparison (comparing the mean weightings of the original data and the measured data, see also Table 3 in the Appendix) were considered satisfactory. These individual scores were also necessary for the execution of the Mann-Whitney U-test as it requires the individual scores of both samples and not merely the mean as it was reported by Swan (2006).
} 


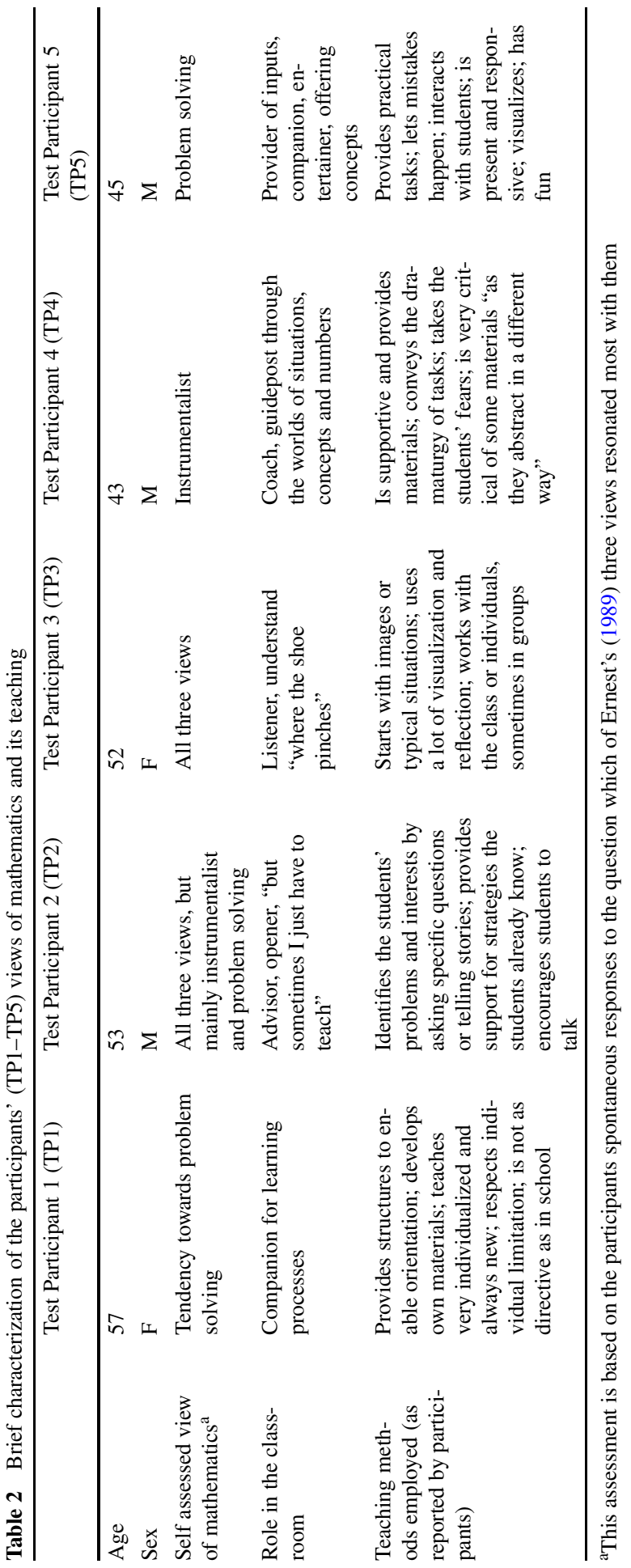


at least partially visually distinct from the other five participants (TP1-TP5, represented as $\bigcirc$ ).

The visual presentation of the data suggests a difference between Swan's group $(N=64)$ and the select five participants of this study. In order to verify the significance of this difference, the Mann-Whitney U-test was applied. This nonparametric test compares two groups without assuming that values are normally distributed and is therefore suitable for very small samples. The test results were significant for two of the three dimensions, namely transmission $(\mathrm{U}=26, p<0.0013 * * *)$ and discovery $\left(\mathrm{U}=285, p<0.01^{* *}\right)$. It is therefore worth noting, that as a first answer to the research question, a clearly constructivist orientation — as defined by Swan — characterizes the reported numeracy teachers' mathematical views. Furthermore, their orientation differs significantly from the group presented by Swan.

\subsection{Interview results}

In a first step a short characterization for each of the five participants is given in Table 2, followed by summarizing the participants' assessment of the video sequences. Combining these results will allow for the description of the key characteristics of the participants' mathematical and teaching beliefs.

Table 2 shows that the participants' views of mathematics are somewhat more diverse than their views of its teaching. While the Platonist view of mathematics is least popular among the participants their preferences for a learner-focused approach to teaching is noteworthy and was to be expected after their clear constructivist orientation identified in the questionnaire. All participants stress the need for identifying the students' available knowledge as a starting point for their classes which puts them as teachers in the role of coaches or mentors in highly individualized teaching situations. This assessment also confirms what has been previously presented in the last line of Table 1, namely that the participants prefer those videos portraying more student centered ( 1 and 5 with eight respectively eleven positive statements) to the more teacher centered approaches (number 4 with ten negative statements). Videos number 2 and 3 present a mixed approach and are assessed accordingly.

The following summary of issues that the participant's addressed in the interviews when talking about the videos, can be considered to at least partially illustrate what the previously identified constructivist overall approach entails. It will be shown, that interactions between teacher and learners as well as the use of language play an important role thereby pointing to a social constructivist orientation. In their assessment of the videos, the most frequent and pertinent comments concern methodological approaches, but also language and infrastructure:

\subsubsection{Methodological approaches}

The participants' comments about some of the specific approaches observed in the videos often relate to their own classroom practices respectively assess their appropriateness for teaching children, teenagers or adults. Four key issues emerge from these comments: 
(i) Activating students: "I have no idea what those students who are not at the blackboard are doing [...] also a missed opportunity to integrate the children more into an activity." (TP3) From various statements it becomes clear that activating students is key and closely related to connecting the respective mathematical theme or problem to the student's reality. Consequently, the absence of references to specific concrete applications when discussing the students' homework (video 4) is criticized.

(ii) Dealing with heterogeneity: "[This assessment is] certainly a method that entails a lot, with which she can maybe also address the children's different levels of knowledge." (TP3) And while the participants stress the need of individualizing their classes, they at the same time acknowledge that this is limited by a specific setting: "She [student in video 5] profits more from this one to one story. The disadvantage is: What can the others profit from it?" (TP5) Successfully dealing with a heterogeneous class can also be seen as a consequence of an individualized approach to teaching and reflects the roles which the participants describe for themselves (see Table 2).

(iii) Appreciating students: Several issues can be summarized under this aspect, namely not exposing students in front of the entire class, valuing the students' knowledge, dealing with mistakes and emotional interaction. Critical voices are not only uttered with respect to the situation of one student standing in front of the entire class at the blackboard, but also at the end of video 3, where the teacher asks all students for the number of points they scored in an informal test: "There is no group in which a person doesn't feel like shit, if you have one point and 90\% got 4.75 points, is there?" (TP2) More specifically, many of the participants criticize that while this assessment was meant to analyze the students' knowledge, the way it was implemented did not leave any room for individual follow up and thereby devaluated it. When talking about mistakes, the participants criticize school for focusing on mistakes and stress the importance of providing the opportunity to make mistakes and learn from them. Last but not least, emotional interaction in general is considered to be important: On one hand all participants comment positively on the fun that the student group in the first video had and how "this element of fun seems to decrease with increasing years of school" (TP4). On the other hand those teachers that interact in a distant or even cool manner with the students are viewed critically.

(iv) Differentiating between a more modern and more traditional style of teaching: Generally the traditional style of teaching is ascribed to those teachers who focus on transmitting specific procedures, while those using a variety of methods are considered to be more modern: "Interesting stuff, a modern way to teach, I think. Here they let the children find out something and the teacher does not exert influence on how the children are doing it, she only intervenes there, where a kind of formal counting mistakes happens." (TP3)

In this context it is also interesting to note that when thinking of their own school experiences the five participants remember predominantly traditional methods: "If I think of my own time at school, this is something completely different." (TP3). 
In short, these statements show that this group of teachers prefers individualized approaches which are closely related to the students' knowledge and personal life and engage them both as acting individuals as well as on the emotional level. And while they favor a so-called modern teaching style, this is not something that the participants remember from their own school experience.

\subsubsection{Language}

The participants are very critical of the teachers' language. The teacher in video 4 introduces checking the problems solved as homework with the remark that the first should not have presented any problems at all. Four out of the five participants comment very critically on this utterance, noting how this-most likely well-meant phrase_-builds up pressure for weaker students: "That is a bad sentence. One should not say that. Because I know from my target group, those who find it difficult, who also try [...] those feel really bad when they hear such phrases." (TP3) Or: "This is also such an incredible expectation, it builds pressure. If I had a problem, oh God. Why such a statement? [...] Maybe it should have been a compliment, you're doing really well, but then it has to be said differently." (TP2) The participants are very much aware of hidden messages that are transmitted with such utterances. The teacher in video 5 never judges the student's answer to be right or wrong, but always says that he agrees or not, upon which one of the participants commented: "What is the objective of this class? [...] The objective is obviously that he agrees. Not that it is right. He agrees, or does not [...] She will walk out of the door and someone will tell her, this is wrong and she will be scared to death. She will find life difficult, because suddenly things are wrong." (TP4) In short, these statements illustrate that the participants are very conscious of hidden messages that are sent with seemingly simple utterances. Furthermore, they seem to be very sensitive to the individual needs and knowledge of the students and they particularly empathize with weaker students, which many of them have in their classes.

\subsubsection{Infrastructure and materials}

It is interesting to note that the participants frequently comment upon the physical appearance of the classrooms. They particularly comment positively on flexible seating arrangements giving the students a chance to move and on one classroom which is decorated with pictures and gives a personal, warm impression. Those sequences where specific material is used which the students could manipulate are also viewed positively: "With this method, this student can grasp something, in the sense of acting understanding." (TP3) All of the participants mention the fact that in video 5 the teacher used available materials to illustrate a problem: "Such things are more comprehensible for people than moving around numbers and Xs." (TP5) But while all of the participants are in favor of working with specific materials and giving students the opportunity to experiment with a variety thereof, they are also critical of related details: "It was a shame that he did not let her get the pins. [...] I think she should have got up [and think for herself] what she could get. That is where it starts, the reference [...] to the world of things. [...] Because she did not 
know what she should have done with them, it did not yet relate to her world." (TP2) Overall it can be said that these statements underline the previously identified issues of an individualized approach where the student with his/her knowledge and experiences stands at the center and teachers take a facilitating role providing a stimulating environment for exploration and linking what happens in the classroom to the student's lives.

The summarized answer to the guiding research question is that presented Swiss adult basic education teachers hold predominantly constructivist views of mathematics and its teaching. This is expressed in their commitment to individualized teaching approaches which relate the mathematical themes to the students' worlds, their interests and previous knowledge thereby stressing important elements of social constructivism. For these participants it goes without saying that the students' questions should be the starting point for any classes. Furthermore, working in a personal atmosphere and respecting students' weaknesses is highly relevant and shows the teachers' concerns for situations in which negative attitudes towards mathematics are developed or reinforced. It is worth noting, that while some of these issues were prominent in the interviews, they were not equally addressed in the questionnaire.

\section{Discussion}

When looking at the presented data it is worth noting that the questionnaire and interview data complement each other well. The latter can be seen to confirm the questionnaire results and serve as illustration of at least some of what the participants' preference for a constructivist view of mathematics and its teaching entails in more detail. Individualized approaches taking the students' problems as starting points imply a facilitating role for the teacher and accepting diverse approaches to doing mathematics. In addition a number of other observations can be identified which tie in with issues often discussed in mathematics education or belief research:

- The relevance of emotional aspects appears in numerous references: the observed fun of the students in a video, the positive atmosphere created in a particular classroom and not least of all the sensitivity towards a teacher's language and implicit messages contained therein. Emotions and mathematics teaching/learning have been discussed under several perspectives, however, only a few typologies of beliefs have integrated them into their categories, such as Andrews and Hatch (1999) who identified one conception of mathematics as a "diverse and pleasurable activity". A more systematic integration of affective issues at this level of describing specific types of beliefs seems desirable.

- Establishing links between mathematics and the students' lives is a key concern for the participants and can possibly be explained with the stance this issue had in their numeracy training course. This is not only expressed at the level of content where they want to see more references to practical applications of specific problems solved, but also at the level of methodologies, where they are highly supportive of using concrete materials and at the same time are very sensitive and critical of how more generic materials are used. As one participant put it: "I'm 
very ambivalent with respect to these materials [Cuisenaire rods or Montessori pearls], because they abstract in another way. It is about something abstract such as mathematics, which for many people is relatively complex and very demanding for their ability to abstract. And then you invent another, second abstract concept, namely that [refers to the abacus used in one video]." (TP4) This illustrates that concrete material is not considered to be positive per se, but that the students need to also understand the idea behind a specific material-something which can present a challenge in addition to understanding a specific mathematical concept.

- The contradiction between how the teachers experienced mathematics during their own school time and how they view it today is only indicative and needs more systematic study. However, it addresses a frequently discussed issue, namely that future teachers enter teacher education with a wealth of experience-and associated beliefs. Addressing and changing these beliefs is one challenge faced by teacher education and the evidence from this group of participants suggests that it is possible, though it remains to be seen what characteristics other specifically trained groups of adult education teachers display. One key factor in this process could be the interaction with students who have failed in/were failed by traditional mathematics teaching, because previous research has identified practical teaching experiences supported by on-going seminars and reflection which also address working with struggling students as a key factor in the development of beliefs (van Zoest et al. 1994)

While these preliminary results point to a number of issues confirming previous results of belief research, there are some limitations to the findings. They include particularly the size of the sample, the use of videos with classroom scenes from school rather than adult education and the lack of classroom observation or other data such as teaching and learning materials. Moreover, while the participants' of Swan's and the presented study share some characteristics, the wider context of their work differs in some aspects: Swan's participants work in colleges therefore in formal education, while the participants of this study work in private institutions offering informal learning opportunities. Another aspect which needs to be born in mind when interpreting the results is the briefly addressed issue of terminology: While participants consider themselves to be numeracy experts, the questionnaire employed primarily addresses mathematics as an educational subject and thereby omits what many consider to be the essence of numeracy, namely its situatedness and relations everyday practice (Yasukawa et al. 2018). This is underlined by the fact that many of these issues came up in the interview data. However, many of these weaknesses could be addressed systematically and compensated in follow-up studies going beyond the exploratory nature of what is presented here. Some ideas in this sense are outlined in the following final paragraphs.

\section{Conclusion}

The exploratory data presented in this article has shown that broadly speaking the mathematical beliefs of the presented group of adult education teachers are char- 
acterized by their constructivist orientation. In this respect the analyzed group of teachers differs clearly from a similar group described by Swan (2006) to which it was compared. Bearing in mind the limitations of this study, it does confirm that a focus on adult education teachers constitutes a potentially fruitful resource for further belief research in general and in relation to numeracy in particular. Learning more about these teachers' beliefs in general and with regard to numeracy in particular fills a knowledge gap and is needed to develop research instruments adequate for the context of adult education. However, is not only interesting from an academic point of view but is also politically and practically relevant in view of the continued importance of building adults' basic skills and lifelong learning for increasingly diverse target groups. On this basis the following proposals are made for potential follow up studies:

- Further explore nuances of beliefs relating to mathematics as a discipline, as school subject and particularly to numeracy as it has previously been done for example by Beswick (2012). When doing so, the role of more recent developments such as changes in the philosophy of mathematics education or the field of digitalization need to be considered.

- Continue to address the relationship of identified beliefs and how they relate to the practice of the teachers holding them. While this has been the focus of many studies (Buehl and Beck 2014), no conclusive answers have been found, yet it is particularly relevant for the quality of education.

- Further develop standardized belief research instruments such as Swan's (2006) questionnaire to incorporate specific aspects of numeracy in the sense of Yasukawa et al. (2018) as well as affective issues.

- Utilize these standardized instruments with large groups of teachers with different trainings and working in various (possibly international) contexts to identify shared and differing aspects of their beliefs and explore how they relate to personal and contextual factors. If possible complement such studies by collecting additional qualitatively different data such as teaching and learning materials in order to better understand the respective contexts.

- Implement long term studies to trace the development of beliefs and how they relate not only to specific trainings but also practical work experience, as it has been done for example by Skott (2013).

These sketched ideas indicate that at the crossroads of three complex fieldsnamely adult education, mathematics/numeracy and beliefs-it seems particularly important to pursue further research using multimethod approaches. In this sense the explorative nature of the presented paper has shown its worth in that it not only confirmed the relevance of the addressed topic and audience, but also the value of using a combination of methods and data where weaknesses in one can be compensated and/or complemented by another.

Open Access This article is distributed under the terms of the Creative Commons Attribution 4.0 International License (http://creativecommons.org/licenses/by/4.0/), which permits unrestricted use, distribution, and reproduction in any medium, provided you give appropriate credit to the original author(s) and the source, provide a link to the Creative Commons license, and indicate if changes were made. 


\section{Appendix}

Table 3 Detailed comparison for the mean weightings of the questionnaire by Swan (2006)

\begin{tabular}{|c|c|c|c|c|c|}
\hline \multirow[b]{2}{*}{$\begin{array}{l}\text { Com- } \\
\text { ponent/ } \\
\text { charac- } \\
\text { teristic }\end{array}$} & \multirow[b]{2}{*}{ Statement } & \multicolumn{2}{|l|}{$\begin{array}{l}\text { Swan (2006) } \\
N=64\end{array}$} & \multicolumn{2}{|c|}{$\begin{array}{l}\text { This study } \\
N=5\end{array}$} \\
\hline & & $\begin{array}{l}\text { Mean } \\
\text { weighting } \\
(\%)\end{array}$ & SD & $\begin{array}{l}\text { Mean } \\
\text { weight- } \\
\text { ing } \\
(\%)\end{array}$ & $\mathrm{SD}$ \\
\hline \multicolumn{6}{|c|}{ Mathematics is: } \\
\hline MT & $\begin{array}{l}\text { A given body of knowledge and stan- } \\
\text { dard procedures } \\
\text { A set of universal truths and rules } \\
\text { which need to be conveyed to stu- } \\
\text { dents }\end{array}$ & 45.2 & 21.3 & 15 & 7.9 \\
\hline MD & $\begin{array}{l}\text { A creative subject in which the } \\
\text { teacher should take a facilitating } \\
\text { role, allowing students to create their } \\
\text { own concepts and methods }\end{array}$ & 29.3 & 14.6 & 66 & 17.8 \\
\hline $\mathrm{MC}$ & $\begin{array}{l}\text { An interconnected body of ideas } \\
\text { which the teacher and the student } \\
\text { create together through discussion }\end{array}$ & 25.5 & 12.8 & 19 & 16.4 \\
\hline \multicolumn{6}{|c|}{ Learning is: } \\
\hline LT & $\begin{array}{l}\text { An individual activity based on } \\
\text { watching, listening and imitating } \\
\text { until fluency is attained }\end{array}$ & 34.8 & 18.1 & 18 & 8.4 \\
\hline LD & $\begin{array}{l}\text { An individual activity based on prac- } \\
\text { tical exploration and reflection }\end{array}$ & 33.4 & 12.8 & 36 & 9.6 \\
\hline $\mathrm{LC}$ & $\begin{array}{l}\text { An interpersonal activity in which } \\
\text { students are challenged and arrive at } \\
\text { understanding through discussion }\end{array}$ & 31.9 & 15.8 & 46 & 13.6 \\
\hline \multicolumn{6}{|c|}{ Teaching is: } \\
\hline TT & $\begin{array}{l}\text { Structuring a linear curriculum for the } \\
\text { students; giving verbal explanations } \\
\text { and checking that these have been un- } \\
\text { derstood through practice questions; } \\
\text { correcting misunderstandings when } \\
\text { students fail to 'grasp' what is taught }\end{array}$ & 41.3 & 18.0 & 15 & 10 \\
\hline TD & $\begin{array}{l}\text { Assessing when a student is ready } \\
\text { to learn; providing a stimulating } \\
\text { environment to facilitate exploration; } \\
\text { avoiding misunderstandings by the } \\
\text { careful sequencing of experiences }\end{array}$ & 29.9 & 11.7 & 38 & 16.1 \\
\hline $\mathrm{TC}$ & $\begin{array}{l}\text { A non-linear dialogue between } \\
\text { teacher and students in which mean- } \\
\text { ings and connections are explored } \\
\text { verbally. Misunderstandings are made } \\
\text { explicit and worked on }\end{array}$ & 28.8 & 16.5 & 47 & 19.2 \\
\hline \multicolumn{2}{|c|}{ Transmission: mean weighting of $M T, L T, T T$} & $40.4(40.86)^{\mathrm{a}}$ & $17.3(17.228)^{\mathrm{a}}$ & 16 & 6.67 \\
\hline \multicolumn{2}{|c|}{ Discovery: mean weighting of $M D, L D, T D$} & $30.8(30.98)^{\mathrm{a}}$ & $10.0(10.387)^{\mathrm{a}}$ & 46.60 & 8.20 \\
\hline \multicolumn{2}{|c|}{ Connectionist: mean weighting of $M C, L C, T C$} & $28.8(28.78)^{\mathrm{a}}$ & $12.1(12.154)^{\mathrm{a}}$ & 37.40 & 10.87 \\
\hline
\end{tabular}

${ }^{a}$ The numbers in brackets are those for the manually recreated values as described in the section on questionnaire results 


\section{References}

Andrews, P., \& Hatch, G. (1999). A new look at secondary teachers' conceptions of mathematics and its teaching. British Educational Research Journal, 25(2), 203-223.

Archer, J. (2000). Teachers' beliefs about successful teaching and learning in English and mathematics: Paper presented at the meeting of the Australian Association for Research in Education. http://www. aare.edu.au/data/publications/2000/arc00325.pdf. Accessed 25 Apr 2019.

Askew, M., Rhodes, V., Brown, M., William, D., \& Johnson, D. (1997). Effective teachers of numeracy: report of a study carried out for the teacher training agency. London: King's College, University of London.

Beeli-Zimmermann, S. (2014). Beyond questionnaires-Exploring adult education teachers' mathematical beliefs with pictures and interviews. ALM International Journal, 9(2), 35-53.

Beeli-Zimmermann, S. (2015). From teaching literacy to teaching numeracy: How numeracy teacher's previous experiences shape their teaching beliefs. Literacy and Numeracy Studies, 23(1), 20-49.

Beswick, K. (2012). Teachers' beliefs about school mathematics and mathematicians' mathematics and their relationship to practice. Educational Studies in Mathematics, 79(1), 127-147.

Buehl, M. M., \& Beck, J.S. (2014). The relationship between teachers' beliefs and teachers' practices. In H. Fives \& M. G. Gill (Eds.), International handbook of research on teachers' beliefs (pp. 66-84). New York: Routledge.

Ernest, P. (1989). The knowledge, beliefs and attitudes of the mathematics teacher: a model. Journal of Education for Teaching, 15(1), 13-33.

Fives, H., \& Gill, M. G. (Eds.). (2014). International handbook of research on teachers' beliefs. New York: Routledge.

Forgasz, H., \& Leder, G. C. (2008). Beliefs about mathematics and mathematics teaching. In P. Sullivan $\&$ T. Wood (Eds.), Knowledge and beliefs in mathematics teaching and teaching development. The international handbook of mathematics teacher education, (Vol. 1, pp. 173-192). Rotterdam: Sense Publishers.

Goldin, G. A., Rösken, B., \& Törner, G. (2009). Beliefs-no longer a hidden variable in mathematical teaching and learning processes. In I.J. Maasz \& W. Schlöglmann (Eds.), Beliefs and attitudes in mathematics education. New research results (pp. 1-18). Rotterdam: Sense Publishers.

Graham, D. J., \& Midgley, N.G. (2000). Graphical representation of particle shape using triangular diagrams: an Excel spreadsheet method. Earth Surface Processes and Landforms, 25(13), 1473-1477.

Henningsen, I., \& Wedege, T. (2003). Values and mathematics: attitudes among teachers in adult education. In I.J. Maasz \& W. Schlöglmann (Eds.), Learning mathematics to live and work in our world. Proceedings of the 10th International Conference on Adults Learning Mathematics, Strobl. (pp. 110-118). Linz: Universitäts Verlag Trauner.

Kaiser, H. (2009). Bausteine für ein Konzept zur Förderung alltagsmathematischer Kompetenz. Zürich: SVEB.

Leder, G. C., Pehkonen, E., \& Törner, G. (Eds.). (2002). Beliefs: a hidden variable in mathematics education? Dordrecht, Boston: Kluwer Academic Publishers.

Liljedahl, P. (2009). Teachers' insights into the relationship between beliefs and practice. In J. Maasz \& W. Schlöglmann (Eds.), Beliefs and attitudes in mathematics education. New research results (pp. 33-43). Rotterdam: Sense Publishers.

Mayring, P. (2014). Qualitative content analysis. Theoretical foundation, basic procedures and software solution. http://nbn-resolving.de/urn:nbn:de:0168-ssoar-395173. Accessed 25 Apr 2019.

Nisbet, S., \& Warren, E. (2000). Primary school teachers' beliefs relating to mathematics, teaching and assessing mathematics and factors that influence these beliefs. Mathematics Teacher Education and Development, 2, 34-47.

O’Donoghue, J. (2002). Numeracy and mathematics. Irish Math Society Bulletin, 48, 47-55.

Pajares, M.F. (1992). Teachers' beliefs and educational research: cleaning up a messy construct. Review of Educational Research, 62(3), 307-332.

Pehkonen, E., \& Törner, G. (2004). Methodological considerations on investigating teachers' beliefs of mathematics and its teaching. Nordisk matematikkdidaktikk, 9(1), 21-49.

Reusser, K., Pauli, C., \& Elmer, A. (2011). Berufsbezogene Überzeugungen von Lehrerinnen und Lehrern. In E. Terhart, H. Bennewitz \& M. Rothland (Eds.), Handbuch der Forschung zum Lehrerberuf (pp. 478-495). Münster: Waxmann.

Schlöglmann, W. (2007). Beliefs concerning mathematics held by adult students and their teachers. In K. Hoskonen \& M. S. Hannula (Eds.), Current state of research on mathematical beliefs XII. Proceed- 
ings of the MAVI-7 Workshop. (pp. 97-109). Helsinki: Department of Teacher Education, University of Helsinki.

Schräder, R., \& Gräminger, B. (2010). Förderung der Grundkompetenzen von Erwachsenen in den Kantonen. Handlungsfelder und Massnahmenideen. https://edudoc.ch/record/94598/files/Analyse_ GoKantone.pdf. Accessed 12 July 2019.

Skott, J. (2013). Understanding the role of the teacher in emerging classroom practices: searching for patterns of participation. ZDM, 45(4), 547-559.

Swan, M. (2006). Designing and using research instruments to describe the beliefs and practices of mathematics teachers. Research in Education, 75(1), 58-70.

Swiss Conference of Cantonal Ministers of Education (EDK) (Ed.). (2018). A portrait. https://edudoc.ch/ record/121270/files/port_edk_e.pdf. Accessed 12 July 2019.

unterrichtsvideos.ch (Ed.). (2008ff). Eine Videoplattform für die Lehrerinnen- und Lehrerbildung. http:// www.unterrichtsvideos.ch. Accessed 25 Apr 2019.

Yasukawa, K., Rogers, A., Jackson, K., \& Street, B. V. (Eds.). (2018). Rethinking development. Numeracy as social practice: global and local perspectives. Abingdon, Oxon, New York: Routledge.

van Zoest, L.R., Jones, G. A., \& Thornton, C. A. (1994). Beliefs about mathematics teaching held by pre-service teachers involved in a first grade mentorship program. Mathematics Education Research Journal, 6(1), 37-55.

Publisher's Note Springer Nature remains neutral with regard to jurisdictional claims in published maps and institutional affiliations. 